\title{
Strengthening Postabortion Family Planning Services in Ethiopia: Expanding Contraceptive Choice and Improving Access to Long-Acting Reversible Contraception
}

\author{
Melaku Samuel, ${ }^{a}$ Tamara Fetters, ${ }^{b}$ Demeke Desta $^{a}$
}

\begin{abstract}
In Ethiopia, a comprehensive strategy to improve postabortion family planning services has produced overall improvement in the uptake of postabortion family planning and a rise in the choice of more effective long-acting reversible contraceptives to produce a more balanced method mix.
\end{abstract}

\begin{abstract}
Where unmet need for the safest, most effective, and long-acting reversible contraceptives (LARCs) is very high, the health system and partners need to implement problem-solving, locally feasible, and comprehensive family planning delivery strategies. Because young and unmarried women are most at risk for unintended pregnancy and repeat abortion due to poor access to contraceptive services, postabortion family planning (PAFP) is a key component in such strategies. In Southern Nations, Nationalities, and People's Region, Ethiopia, lpas implemented health system strengthening efforts from fiscal year (FY) 2010 (July 2009 to June 2010) to FY 2014 (July 2013 to June 2014) to improve the quality of PAFP services and expand method choice in 101 public facilities. The intervention significantly improved PAFP uptake at the project sites. Specifically, the proportion of abortion clients receiving LARCs progressively improved during the intervention period. The proportion of abortion clients who left the facilities with a contraceptive method increased from 58\% in FY 2010 to $83 \%$ in $\mathrm{FY} \mathrm{2014.} \mathrm{The}$ share of method mix for LARCs rose from 2\% in FY 2010 to 55\% in FY 2014, while the share for condoms, injectables, and oral contraceptives declined from $98 \%$ to $45 \%$. Implant use rose from $2 \%$ in FY 2010 to $43 \%$ in FY 2014, while the use of intrauterine devices increased from $0.1 \%$ in FY 2010 to $12 \%$ in FY 2014. A larger proportion of PAFP users received LARCs at health centers, where midwives and nurses are the primary providers, than at hospitals (59\% versus $37 \%$, respectively). A broader method mix can satisfy clients with a variety of needs, a key factor for higher uptake of more effective methods and program success. Further evidence-based interventions need to be implemented to improve the quality of PAFP in a feasible and replicable strategy that addresses unmet need for modern contraceptive methods.
\end{abstract}

\section{INTRODUCTION}

$\mathbf{I}^{\mathrm{n}}$ Ethiopia, as throughout the world, low levels of contraceptive use lead to high levels of unintended pregnancy, the root cause of induced abortion. The first nationally representative study in Ethiopia, conducted in 2008, revealed that $42 \%$ of all pregnancies were unintended, and an estimated 382,500 induced abortions were performed over a l-year period, for an annual rate of 23 abortions per 1,000 women of reproductive age. ${ }^{1}$ Many of these abortions were still performed with questionable levels of safety and efficacy outside of health facilities. Women seeking induced abortion had a mean age of 23,

\footnotetext{
alpas, Addis Ababa, Ethiopia.

blpas, Chapel Hill, NC, USA.

Correspondence to Melaku Samuel (samuelm@ipas.org).
}

and the majority (57\%) were single. Among women seeking induced abortion, only $24 \%$ reported contraceptive use prior to the current pregnancy. The same study also found that 1 of every 4 facilities in the country did not have designated postabortion contraceptive services for women who had received abortion care. ${ }^{1}$

It is estimated that as many as $95 \%$ of unintended pregnancies in Ethiopia occur among women who do not practice contraception at all. ${ }^{2}$ The national Demographic and Health Survey in 2011 found that 1 of every 4 married women had an unmet need for family planning, and nearly $29 \%$ of most recent births and current pregnancies were reported as either mistimed or unwanted. ${ }^{3}$

The high unmet need for contraception coupled with high numbers of safe and unsafe abortions testifies to 
the need for stronger routine contraceptive services and highlights the potential benefits of strengthening postabortion contraceptive services. Postabortion family planning (PAFP) involves provision of voluntary contraceptive counseling and methods to women after abortion care, whether for induced abortion or the treatment of complications from an unsafe abortion, to reduce unintended pregnancies and repeat abortions. International organizations in the field of reproductive health and health researchers have posited that PAFP services that respect women's sexual and reproductive rights are an ideal way to reach sexually active women with unplanned pregnancies, including young women who may have had limited exposure to modern contraception. ${ }^{4-9}$ Studies and interventions conducted in different parts of the world have shown that PAFP improves women's knowledge of the benefits of contraception and increases uptake of contraceptive methods immediately after abortion, when return to fertility is almost immediate. Women's motivation to continue using a method is also likely to increase after leaving the facility. ${ }^{10-14}$

Although many factors may constrain family planning programs, a limited method mix has been shown to adversely affect both contraceptive acceptance and continuation postabortion as well as the overall achievement of a national family planning program. ${ }^{15,16}$ Family planning programs, especially those for PAFP, should offer a range of methods in order to meet the various needs of their clients. ${ }^{4,7,8}$ Evidence has shown that introducing a wider range of contraceptive methods in PAFP significantly increases the proportion of clients leaving the facility with a method. ${ }^{12,17}$ The benefits of contraception can be particularly important for postabortion contraceptive acceptors: Many postabortion clients face high risk of maternal mortality due to high parity or the likelihood that their pregnancies could end in unsafe abortion. ${ }^{18}$ Moreover, comprehensive PAFP counseling is likely to promote the choice of more effective methods as women learn more about less common contraceptive options. ${ }^{19-21}$ Including more effective methods in the method mix can enhance program impact; use of longterm, highly effective methods such as intrauterine devices (IUDs) and contraceptive implants is likely to prevent more unplanned pregnancies and decrease demand for abortion. ${ }^{20,22}$

Cognizant of the broader benefits of PAFP services to the reproductive health of women and the Ethiopian National Family Planning Program, the international NGO Ipas has implemented an evidence-based health systems strengthening intervention to improve PAFP uptake. The intervention has focused on achieving a more balanced contraceptive method mix by increasing use of long-acting reversible contraceptives (LARCs). Although the intervention took place in 4 major regions of the country, this article presents only the approaches, achievements, and lessons learned from 101 public health facilities in the Southern Nations, Nationalities, and People's Region (SNNPR) of Ethiopia between fiscal year (FY) 2010 (July 2009 to June 2010) and FY 2014 (July 2013 to June 2014).

\section{MOVING FROM POSTABORTION CARE TO COMPREHENSIVE ABORTION CARE}

Since 2002 Ipas Ethiopia, as one of the major partners of the Ethiopian health sector, has been supporting the Ministry of Health (MOH) to improve the delivery and quality of abortion care and PAFP services. Before revision of law in 2005, all facilities were expected to provide only postabortion care (PAC), including postabortion contraception, for the management of incomplete abortion and complications resulting from induced or spontaneous abortion. Following legal reform that expanded the indications for safe abortion services, ${ }^{23}$ the $\mathrm{MOH}$ and its technical partners worked extensively to introduce a comprehensive abortion care (CAC) model. The model is an integrated set of sexual and reproductive health services that include safe induced abortion for all legal indications, treatment of incomplete and unsafe abortion, counseling, and provision of contraception and other reproductive health services as needed. Despite these efforts, however, service data revealed a low rate of uptake of contraception after abortion care and a highly skewed method mix in most facilities.

A baseline facility assessment in 2008 identified a number of gaps and barriers. Only $47 \%$ of health centers in SNNPR provided postabortion contraception-most often because they provided no abortion care at all. ${ }^{24}$ Only $8 \%$ of all facilities offered IUDs, and only $28 \%$ offered implants. Factors identified as limiting the availability or quality of PAFP services included:

- Gaps in service providers' knowledge: Although PAC services were widespread in the country at the time, an assessment of these services conducted in 2000 found that more

\author{
In 2008, among \\ women seeking \\ induced abortion, \\ only $24 \%$ reported \\ contraceptive use \\ prior to the current \\ pregnancy.
}




\section{Increasing uptake of postabortion contraception and improving the method mix, with special attention to LARCs, was a major focus of the intervention.}

than three-quarters of PAC providers had never received any special training in family planning counseling or service delivery. ${ }^{25} \mathrm{~A}$ later assessment of facilities in SNNPR, conducted in 2008, reported that only half of health facilities had providers capable of providing LARCs or permanent methods. ${ }^{24}$

- Shortages of contraceptive commodities, equipment, and supplies: Keeping a wide range of contraceptive methods in stock in facilities and in the abortion services areas was another weakness in PAFP service. At the time of the baseline assessment, less than one-quarter of facilities had implant insertion and removal kits, and only 5\% had insertion and removal kits for IUDs. ${ }^{24}$ Oral contraceptives were universally available, however, and injectable contraceptives were available in $97 \%$ of facilities. ${ }^{25}$

- Lack of designated service delivery space for PAFP: Most facilities (88\%) provided PAFP services in the maternal and child health or family planning units, separate from the locations of PAC services. ${ }^{25}$ Most clients were asked to go elsewhere in the facility to receive contraception, were given a referral, or were asked to return at another time. Many health centers (and some hospitals) provided abortion care and PAFP services in delivery rooms, often with a limited mix of contraceptive methods, if they were available at all.

- No special focus for young women and adolescents: World Health Organization (WHO) guidance recommends that all reproductive health programs and services address the special needs of adolescents and young women. ${ }^{4}$ Young and adolescent women are more vulnerable to unwanted pregnancy and unsafe abortion because they are less likely to have initiated contraception. Therefore, services for these women need to be both more comprehensive and focused on their needs. However, site observations in the project area indicated that most facilities were unable to provide effective and accessible services to young clients that took into account their special needs, such as privacy and confidentiality throughout the continuum of their care. One major problem was a lack of training and continuing support to health care providers to improve their knowledge and skills on the package of interventions and service delivery approaches for young and adolescent women.
- Poor referral linkages between facilities and community-based programs: Wellestablished referral linkages and technical assistance agreements between abortionproviding facilities and community partners that provide contraceptive services and information were often lacking, contributing significantly to underutilization of services. ${ }^{24}$

\section{KEY COMPONENTS OF THE INTERVENTION}

After identification of these major service delivery gaps, Ipas staff and $\mathrm{MOH}$ partners designed and implemented problem-focused interventions to improve service delivery standards and provide accessible, high-quality PAFP services acceptable to all clients. The ultimate goal of the intervention was to improve all components of comprehensive abortion care. However, increasing the uptake of postabortion contraception and improving the contraceptive method mix, with special attention to LARC methods, was a major focus.

The effort to increase uptake of PAFP and of LARC methods especially included 8 key elements:

- Integration of CAC and comprehensive contraceptive trainings

- Improving the availability of contraceptive commodities and related equipment

- Renovation, refurbishment, and reorganization of CAC and PAFP service delivery sites

- A quality improvement initiative

- Promotion of youth-friendly services

- Clinical mentoring and programmatic supports to providers

- Strengthening community-facility linkage through involvement of health extension workers

- Integrating reproductive autonomy into contraceptive method selection

\section{Integration of Comprehensive Abortion Care and Comprehensive Contraceptive Trainings}

Although many abortion care providers had received some exposure to postabortion contraceptive provision, the project made a renewed effort to improve their skills. All CAC providers participated in an updated training on comprehensive contraception. The new curriculum emphasized scientific and technical updates concerning 
LARC methods, as this had been identified as a particular weakness. Contraceptive trainings employed both didactic and practical training to improve the clinical skills necessary to provide IUDs and implants. The curriculum stressed the elements of high-quality family planning counseling services as recommended by WHO. ${ }^{15}$ These include a renewed emphasis on free and voluntary choice of a method. The contraceptive/LARC training was primarily designed for mid-level providers-midwives, nurses, and health officers-the cadres largely responsible for providing reproductive health services, including abortion care, at the primary health care level.

Between July 2009 and June 2014, 545 midlevel providers from 101 facilities received training in comprehensive contraception. ${ }^{26}$ Almost all of these providers were also trained to provide comprehensive abortion care. A pilot initiative designed to expand integrated PAC services at the primary care level through support to midwives (such as in-service training and supervisory and logistics support) led to improved access to PAFP services-70\% of PAC clients received PAFP services. ${ }^{27}$ By comparison, before the initiative there was no routine system of postabortion counseling in the region and only minimal efforts to break the cycle of unintended pregnancy and unsafe abortion.

\section{Improving the Availability of Contraceptive Commodities and Related Medical Equipment}

Oral contraceptives, injectable contraceptives, IUDs, contraceptive implants, and condoms should be available at all facilities; permanent methods performed surgically - tubal ligation and vasectomy-are available only at hospitals. Based on gaps identified in the intervention facilities, facilities began to regularly receive supplies of IUDs, implants, and essential family planning kits (such as medical equipment and supplies required for insertion and removal of IUDs and implants). In addition, hospitals received mini-laparotomy and no-scalpel vasectomy kits. From 2008 through 2012, a total of 92 IUD insertion and removal kits and 12 voluntary surgical contraceptive kits (minilaparotomy and no-scalpel vasectomy kits) were distributed to the facilities in SNNPR. ${ }^{26}$ Ipas also provided the $\mathrm{MOH}$ regional health system with technical assistance to establish a sustainable supply of commodities and equipment for comprehensive abortion and contraceptive provision. Pharmacy personnel in health facilities received orientation to the products and to forecasting and procurement through the government supply system.

\section{Renovation, Refurbishment, and Reorganization of Service Delivery Sites}

Service delivery experiences in various countries have shown that providing counseling and postabortion contraception at the same time and location where abortion services are provided can reduce missed opportunities and enhance acceptance of PAFP. ${ }^{14,20}$ With these benefits in mind, Ipas provided financial, material, and technical support to 53 facilities to renovate, refurbish, and reorganize service sites based on the identified needs in each facility. The work significantly improved privacy, confidentiality, infection prevention practices, and the organization of services to provide abortion and PAFP services. The upgraded service delivery areas also improved providers' motivation and commitment to provide high-quality, integrated care.

\section{The Quality Improvement Initiative}

This initiative was pilot-tested in 12 facilities (9 health centers and 3 hospitals) randomly selected from among Ipas-supported sites in SNNPR. During the pilot-test period, all progress and changes in the quality of abortion care indicators were monitored and documented at regular intervals. At the conclusion of the pilot program, significant improvement had been achieved in most of the key quality indicators for CAC services, including PAFP. ${ }^{28}$ One objective of the pilot-test was to produce recommendations for scaling up simple, practical quality improvement tools that can be integrated into the existing program monitoring system. Based on lessons learned from the pilot exercise, such practical monitoring tools as simple sitelevel indicators and on-site exercises for service improvement were integrated into the routine supervisory processes and replicated in the other sites in the region. Reminders were posted in CAC service areas on such quality-of-care points as abortion procedure protocol and clients' rights to informed choice, privacy, and confidentiality during service delivery.

\section{Promotion of Youth-Friendly Services}

Almost $60 \%$ of women receiving abortion care at Ipas-supported sites are under age 25. Thus, it was imperative to raise the awareness of service providers about the needs and circumstances of 


Trainings for
HEWs focused not
only on skill
building but also
on creating a
strong referral
linkage,
particularly for
clients seeking
long-acting or
permanent
methods.

young women. To improve access to comprehensive abortion care for young women, a pilot project was initiated in 12 of the SNNPR project facilities. This initiative focused on:

1. Training providers in accord with national standards and guidelines

2. A minimum service delivery package of youth-friendly services

3. Support for reorganization of services for potential youth beneficiaries ${ }^{29}$

The facilities received technical and financial support to make the service delivery setup more convenient for young clients and to provide contraceptives in the abortion procedure rooms, which helps to ensure privacy and confidentiality during service delivery. Also, facilities were equipped with information materials, furniture, and audiovisual aids to attract and serve young people.

Facilities were encouraged to integrate comprehensive abortion care with all other reproductive health services, such as care for sexually transmitted infections, including HIV. Efforts were also made to establish and improve the referral networks between other facilities, community-level health services, and youth-focused organizations. After reviewing the lessons and challenges learned from the pilot initiative, all other facilities in the project sites integrated the service approach into their CAC services.

\section{Clinical Mentoring and Programmatic Supports to Providers}

Training alone does not always ensure that providers are competent and confident and able to put all their skills into practice. In this intervention newly trained providers received needs-based on-site clinical mentoring by senior and seasoned providers from the same facility. The providers requiring clinical support were identified at the end of the training or while providing services and linked with on-site mentors. The mentors provided more intensive clinical support, as frequently as necessary. In addition, all newly trained providers were contacted within 3 to 4 weeks after training to ascertain whether they had begun offering services and to provide clinical and programmatic support. To promote sustainability, all programmatic support was coordinated with $\mathrm{MOH}$ regional staff and facility management.

\section{Strengthening Community-Facility Linkage Through Involvement of Health Extension Workers}

In Ethiopia health extension workers (HEWs) have responsibility for community-level reproductive health services, including counseling and provision of some contraceptive methods and referrals for others. A study on utilization of PAC services found that community providers can play an important role in improving community awareness of abortionrelated issues, overcoming stigma, and disseminating information on the availability of services. ${ }^{30}$ Ipas conducted orientation workshops for 368 HEWs on long-acting contraception, myths and misconceptions about IUDs, unwanted pregnancy, and comprehensive abortion care. The trainings focused not only on skill building but also on creating a strong referral linkage between health facilities for abortion care and community health programs for contraceptive services, particularly for clients seeking longacting or permanent methods. To improve HEWs' counseling skills, the WHO decision-making tool was distributed to all HEWs in the intervention areas. In addition, abortion care providers and reproductive health coordinators from the $\mathrm{MOH}$ participated in orientation workshops to develop formal agreements for providing mentoring for HEWs and establishing more effective referral linkages between facilities and community health services.

\section{Integrating Reproductive Autonomy into Contraceptive Method Selection}

While this intervention focused on eliminating barriers that impede postabortion contraceptive acceptance and contribute to a skewed method mix, it was important to do so while respecting and emphasizing women's reproductive autonomy. All training packages include sessions on reproductive rights and effective counseling steps, emphasizing the responsibility of service providers to assure that clients can make informed, voluntary choices concerning their abortion procedures and contraception. Training for reproductive health officers and on-site exercises, adapted from the COPE for Comprehensive Abortion Care manual, provided information and practice for providers about clients' rights to information, choice, and safe services. ${ }^{28}$

\section{METHODS}

\section{Data Collection Methods and Tools}

Through routine monitoring, project staff regularly collected and reviewed service data from all 
intervention facilities ( 78 facilities in FY 2010 and FY 2011, 95 in FY 2012 and FY 2013, and 101 in FY 2014). From FY 2010 to FY 2012, data were collected quarterly; in subsequent years, semiannually. Zonal health department staff members, along with Ipas program coordinators, were responsible for data collection, extracting information from the abortion services logbook using a data collection form developed for this purpose. Data collected include information on the type of abortion care, abortion technology, age category, gestational age of the pregnancy, and postabortion contraceptive method chosen by each woman.

\section{Data Management, Analysis, and Use}

Data were entered into a Microsoft Excel database and a national online database to conduct descriptive analysis, review trends, and monitor progress. Service data were analyzed and used at facility, district, zonal, and regional levels to review achievements and identify challenges requiring action. Wall charts were developed and displayed at the facilities to track service utilization and postabortion contraceptive methods chosen using data in the aggregate. Regional program review meetings for CAC/PAFP providers and zonal and district program staff took place semiannually.

PAFP uptake and indicators of the pattern of method use presented in this article are based on descriptive analysis of these service data. The study team focused on changes in the distribution of method use in the health centers compared with the hospitals, as well as PAFP uptake compared with results of the stand-alone family planning program in the same facilities. Bivariate analysis used chi-square tests to examine the differences in method use patterns between different categories. Statistical significance was established at $P<.05$.

Data were collected by the program for the purpose of continuous quality improvement, not for the purpose of conducting systematic research in a strictly defined model. All data analysis was conducted according to international principles of maintaining privacy and confidentiality of personal information.

\section{RESULTS}

Between July 2009 and June 2014, a total of 44,682 women sought abortion care in 101 public health facilities in the region. Among all women who sought care, 34,212 (77\%) received safe and legal induced abortions; the remaining 10,470 women $(23 \%)$ received postabortion care for complications of unsafe abortions or complicated miscarriages.
Most women, $60 \%$, were young; only $40 \%$ of women who sought abortion care during this period were older than 24.

\section{Uptake Increased and Method Mix Improved}

Service delivery data showed progressive improvement in the uptake of postabortion contraception in intervention facilities. The proportion of abortion clients who left the intervention facilities with some form of contraception increased from 58\% in FY 2010 to 83\% in FY 2014 (Figure 1).

The package of interventions also progressively changed the contraceptive method mix, particularly the proportion of women accepting LARC methods. Figure 2 shows that the proportion of CAC clients who accepted a method and chose short-acting hormonal methods, mainly injectable and oral contraceptives, declined from $98 \%$ in FY 2010 to $45 \%$ in FY 2014. The proportion of all CAC contraceptive acceptors who chose a long-acting method rose from $2 \%$ in FY 2010 to $55 \%$ in FY $2014(P<.001)$. The average annual rate of increase in LARC method acceptance was $13.3 \%$; the highest increment, of $21 \%$, occurred between FY 2010 and FY 2011. In addition, among all CAC clients, in FY 2010 about 57\% chose short-acting methods, while only $1 \%$ chose LARCs. After 5 years of the intervention, the proportion choosing shortacting methods decreased to $37 \%$, whereas the percentage choosing LARCs climbed to $46 \%$.

Figure 3 illustrates the changes in the method mix specifically for long-acting and permanent methods during the intervention period. The share of implants as a percentage of all method use rose quickly, from $2 \%$ in FY 2010 to $43 \%$ in FY 2014, while IUD acceptance increased from only $0.1 \%$ in FY 2010 to $12 \%$ in FY 2014. Female sterilization (tubal ligation) remained the least chosen method, with very few CAC clients ( 3 in FY 2013 and 17 in FY 2014) choosing voluntary surgical contraception to limit childbearing.

\section{Contraceptive Acceptance Higher in Health Centers Than in Hospitals}

Disaggregating postabortion contraceptive service data by facility type revealed higher contraceptive acceptance in health centers $(86 \%$ of all women left with a method) than in hospitals, where $71 \%$ of abortion clients left with contraception. Figure 4 shows that the method mix was more balanced in health centers than in hospitals. For example, in FY 2014 the proportion in hospitals choosing

\section{The proportion of clients who left with contraception increased, and the method mix improved.}


FIGURE 1. Proportion of Comprehensive Abortion Care Clients Who Left the Facility With a Contraceptive Method by Year, SNNPR, Ethiopia, FY 2010-14 (N=44,682)

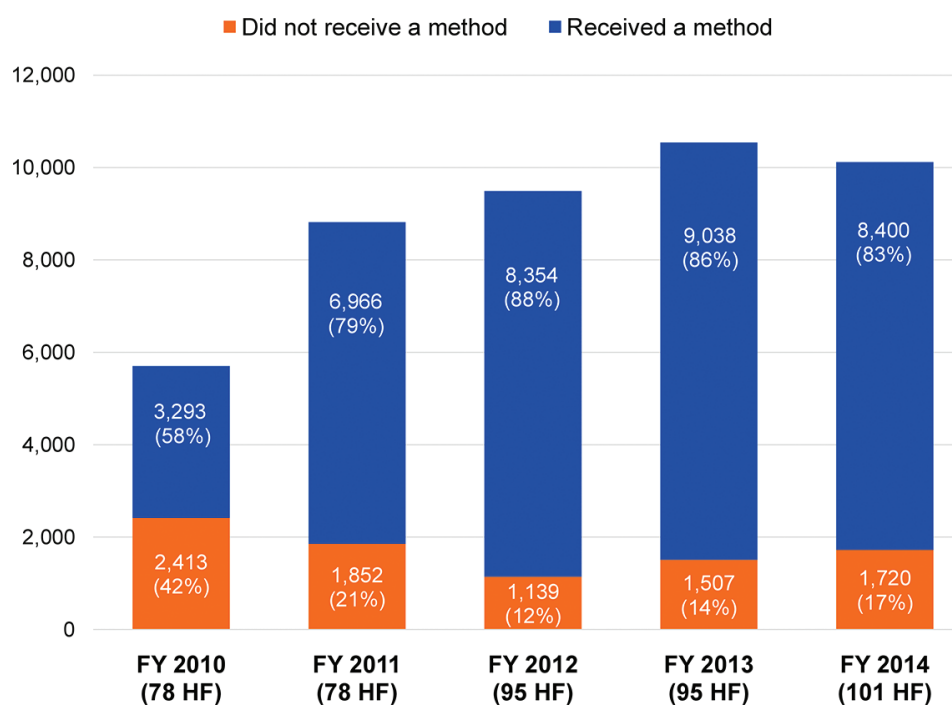

Abbreviations: FY, fiscal year; HF, health facilities; SNNPR, Southern Nations, Nationalities, and People's Region.

long-acting methods was only $37 \%$, while $59 \%$ of women cared for in health centers chose a LARC method after their abortion care $(P<.01)$.

\section{Choice of LARC Methods Higher in Comprehensive Abortion Care Areas Than in Routine Services}

As Figure 5 shows, comparing LARC acceptance in the comprehensive abortion care areas with the routine family planning services in the same sites indicates that the rate of LARC acceptance among postabortion clients, averaging $55 \%$, was much higher than in the same facilities' routine family planning programs, where on average only $23 \%$ chose LARC methods $(P<.001)$. Among those choosing long-acting methods, the proportion choosing IUDs $(21 \%)$ was also higher among postabortion clients than in routine family planning services, where only $15 \%$ of such clients chose IUDs. Trend analyses of LARC uptake in the routine programs showed that the proportion of implant acceptors increased from 3\% in FY 2010 to $19 \%$ in FY 2014, while IUD acceptance increased far more slowly, from only $0.1 \%$ to $4 \%$ of all methods over the same time period.

\section{DISCUSSION}

The package of interventions introduced in service expansion in SNNPR during the past half-decade tested the impact of focused attention to postabortion service quality on the uptake of contraceptive methods, particularly on the choice of long-acting methods. In addition to increased attention to postabortion contraception, the rights-based approach to informed consent and decision making emphasized the importance of contraceptive choice and ensured providers' commitment to the sexual and reproductive rights of women. While the purpose of the project was to improve postabortion service quality overall, benefits included an increase in postabortion choice of a contraceptive method and a greater proportion choosing the more effective, long-acting methods.

As the result of this intervention, the proportion of abortion clients who received contraception increased from $58 \%$ to $83 \%$, a rate in line with other countries' achievements implementing similarly intensive strategies to improve services. ${ }^{11,12,14,16}$ For instance, in a similar pilot initiative in Turkey to integrate family planning with abortion services, the proportion of abortion clients who accepted 
contraceptive methods rose from $65 \%$ in 1991 to $98 \%$ in $1992 .{ }^{11}$ Findings from around the world show that provision of family planning counseling and services immediately after all types of abortion care can increase the postabortion contraceptive acceptance rate from $0 \%-10 \%$ pre-intervention to $50 \%-80 \%$ within 1 to 2 years after the intervention. ${ }^{7,10}$

\section{Increased Choice of Long-Acting Methods}

One notable achievement of this particular program intervention was the significant uptake of long-acting methods, which were greatly underutilized before the intervention. Over the intervention period, some CAC clients who would have chosen short-acting methods now chose LARCs instead. As the overall proportion of PAFP acceptors increased, some new CAC clients who would not have taken any method now also chose LARCs. Key strategies to this end were improving the availability of long-acting methods and related equipment, providing clinical and contraceptive training for mid-level providers, and encouraging and facilitating provision of all contraceptive methods in the same location where abortion services are provided. Similar components of the intervention in Turkey significantly improved the acceptance of LARC methods. ${ }^{11}$ Furthermore, a randomized trial in China found that a comprehensive postabortion care package increased the use of more effective contraception, such as IUDs and implants, when compared with a minimum package of services. ${ }^{19}$

LARC methods should be an integral part of a comprehensive method mix since they are more effective than short-acting methods and so better prevent repeat abortions. A study in the clinics of Planned Parenthood Northern California found that immediate insertion of IUDs postabortion significantly reduced unwanted pregnancy compared with other contraceptive methods or delayed IUD insertion; women who received an IUD immediately postabortion had only 35 abortions per 1,000 woman-years of follow-up compared with 91 for the comparison group. ${ }^{22}$

Women who sought postabortion care at health centers in SNNPR were more likely to accept postabortion contraception and to choose a longacting method than women who sought postabortion care in hospitals. While this finding needs further investigation, there is evidence in other parts of Africa as well that decentralization of services from hospitals to lower-level facilities has
FIGURE 2. Trends in Use of Short-Acting and Long-Acting Methods Among Postabortion Contraceptive Acceptors by Year, SNNPR, Ethiopia, FY 2010-14 (N=36,051)

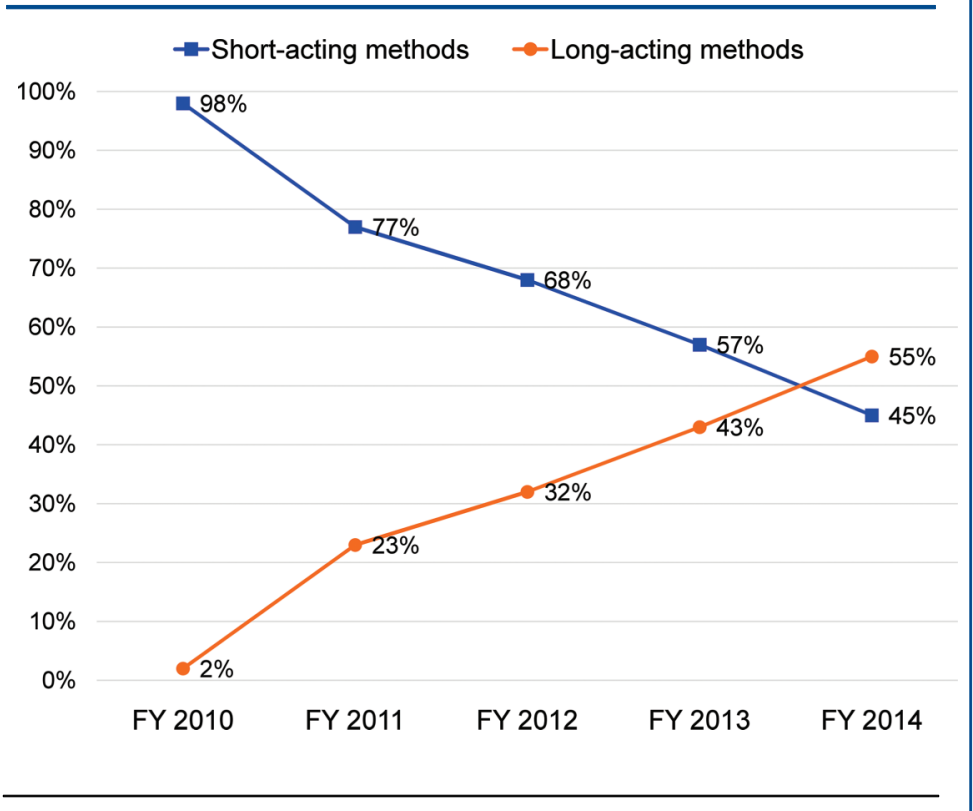

Abbreviations: FY, fiscal year; SNNPR, Southern Nations, Nationalities, and People's Region.

increased the uptake of postabortion contraception. For example, a pilot project in Tanzania to assess the feasibility of expanding PAC services to health centers and dispensaries reported that $91 \%$ to $100 \%$ of clients received postabortion counseling, and $97 \%$ to $100 \%$ of those clients left the locations with a method, except in the few facilities that did not adhere to the intervention. ${ }^{31}$ Moreover, public health experts agree that abortion care and contraceptive services need to be decentralized to improve availability and quality by making services more accessible to women in rural areas and to reduce overcrowding in tertiary hospitals. ${ }^{6}$

Most women who chose a long-acting method chose an implant (79\% of all LARC acceptors). Women's method preferences were likely to be affected not only by the counseling they received but also by educational information campaigns in the region. ${ }^{15}$ During the study period, the federal and regional governments conducted extensive educational campaigns on contraceptive implants to promote use of this method. In fact, a recent study exploring knowledge and acceptance of longacting and permanent methods in southeastern Ethiopia found that reproductive-age women were

\author{
Providing family \\ planning \\ counseling and \\ services \\ immediately after \\ abortion care can \\ increase the \\ postabortion \\ contraceptive \\ acceptance rate \\ from $0 \%-10 \%$ \\ pre-intervention \\ to $50 \%-80 \%$ \\ within 1-2 years.
}


FIGURE 3. Trends in the Method Mix Among Postabortion Contraceptive Acceptors by Year, SNNPR, Ethiopia, FY 2010-14 ( $\mathrm{N}=36,051)$

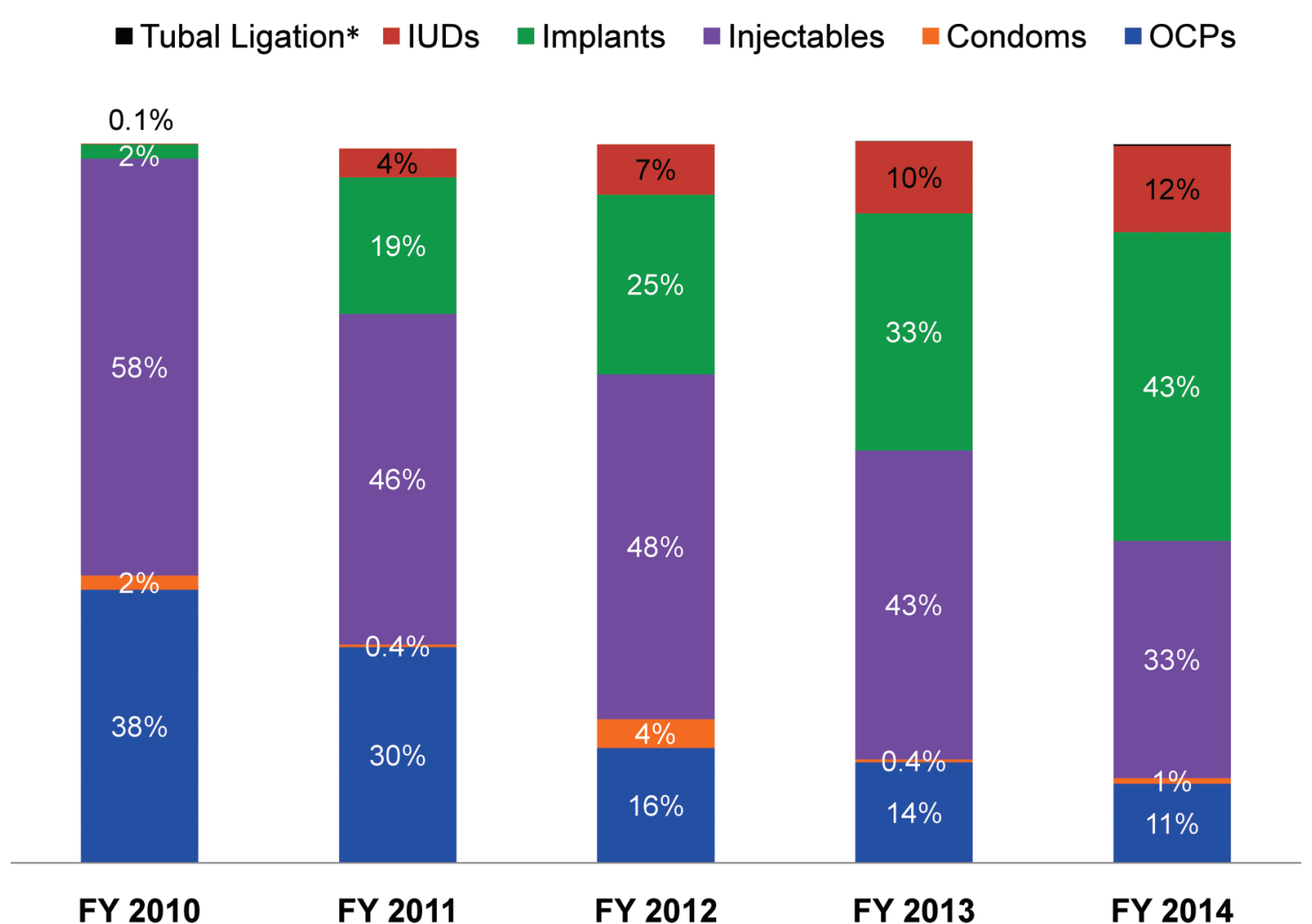

Abbreviations: FY, fiscal year; IUDs, intrauterine devices; OCPs, oral contraceptive pills; SNNPR, Southern Nations, Nationalities, and People's Region.

* Values for tubal ligation were $0 \%$ in 2010,2011 , and 2012; $0.03 \%$ in 2013; and $0.2 \%$ in 2014.

most knowledgeable about contraceptive implants. Some $87 \%$ of married women reported that they had heard of Norplant contraceptive implants. ${ }^{32}$

In the project sites, IUDs have become a more common selection and are now the choice of $21 \%$ of all LARC method acceptors in the abortion care areas of these facilities. However, lack of awareness and local misconceptions about the IUD, such as fear of infertility and infection, still persist across Ethiopia. ${ }^{32}$

Similar service improvement strategies have been employed to shift the method mix and increase use of long-acting methods in routine family planning programs in the region. The achievement has not been as satisfactory as in abortion care areas, however. It seems likely that the longer interactions between providers and abortion clients in the abortion care settings results in more thorough counseling; clients are counseled during the pre-, intra- and post-procedure times. This finding is in line with those of a study in southeastern Ethiopia that selection of long-acting and permanent methods was significantly associated with the number of times that clients and providers discussed these methods. ${ }^{32}$ Also, abortion clients may have a higher unmet need for long-acting methods because of their youth; a large proportion are unmarried but sexually active, wanting to delay marriage and childbearing.

\section{Limitations of the Study}

The findings presented here provide results from a large intervention for women who sought either 
FIGURE 4. Contraceptive Method Use Patterns Among Postabortion Contraceptive Acceptors by Type of Facility, SNNPR, Ethiopia, FY 2014

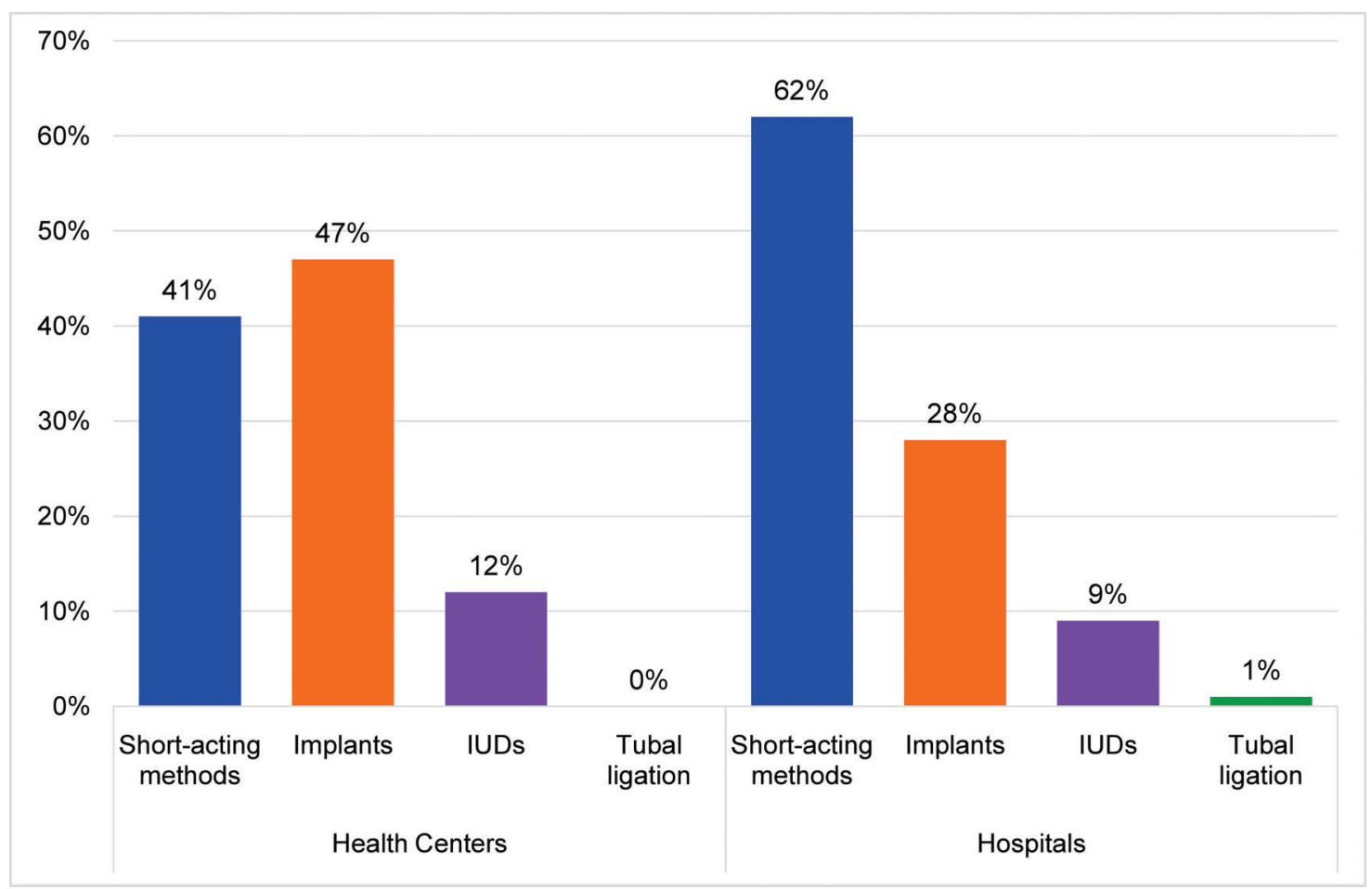

Abbreviations: IUDs, intrauterine devices; SNNPR, Southern Nations, Nationalities, and People's Region.

induced abortion or postabortion care in more than 100 public health facilities. These findings are based on service data from intervention sites; they may not be generalizable to all facilities in the region, the country, or the private sector. However, this research was conducted in partnership with the Ethiopian $\mathrm{MOH}$ at all levels, and, as such, it should be seen as describing a replicable, low-cost model for scaling up services in Ethiopia and elsewhere. No efforts were made to control for community or national efforts to increase family planning acceptance in the general population, and so it is not possible to attribute all of the gains made in this study period to the package of service delivery interventions. Findings are meant to describe and provide a platform for comparison and lessons learned. The large size of the program and the scope of data collection make possible further research to explore the association of sociodemographic factors (such as marital status, parity, education, occupation, previous use of contraception, and abortion history) with the type of abortion care, procedure, and contraceptive method acceptance. This program has recently begun a phase-out strategy aimed at ensuring self-reliance among high-performing facilities to sustain delivery of comprehensive abortion care without routine NGO support.

\section{RECOMMENDATIONS AND CONCLUSIONS}

\section{Family Planning Programs Can Fail in 3 Ways}

Reproductive health organizations and experts have emphasized 2 potential failures in any family planning program that allow the vicious cycle of unintended pregnancy and abortion to persist. The first failure would be the inability of
This research was conducted in partnership with the Ethiopian $\mathrm{MOH}$ at all levels and, as such, should be seen as describing a replicable, lowcost model for scaling up services in Ethiopia and elsewhere. 
FIGURE 5. Contraceptive Method Use Patterns Among Comprehensive Abortion Care Clients Versus Clients of Routine Family Planning Services, SNNPR, Ethiopia, FY 2014

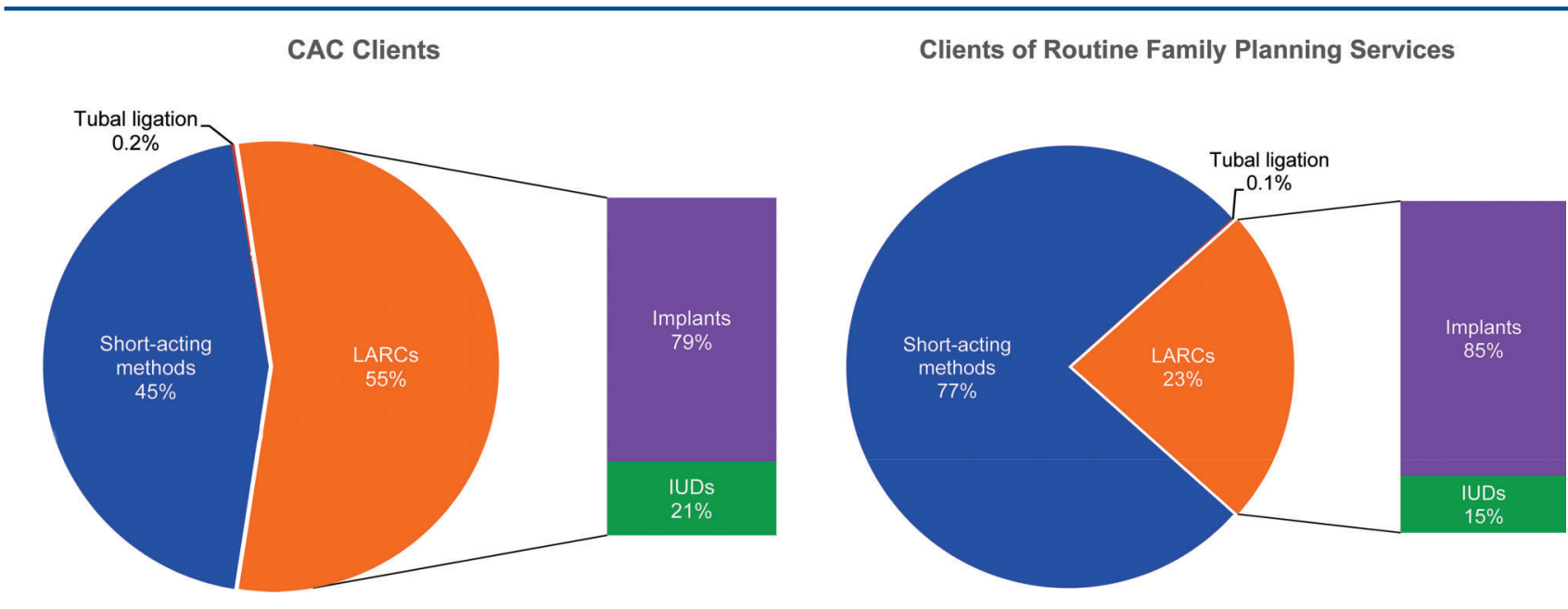

Abbreviations: IUDs, intrauterine devices; LARCs, long-acting reversible contraceptives; SNNPR, Southern Nations, Nationalities, and People's Region

\section{Comprehensive \\ abortion care \\ requires a wide \\ range of \\ contraceptive \\ methods, \\ adequate \\ infrastructure, and \\ well-trained \\ providers, among \\ other factors.}

Young and single women need long-term and reliable protection for their long reproductive lives ahead. the program to prevent unwanted or mistimed pregnancy. The second potential failure would be when a woman who received abortion services leaves without the means to prevent another pregnancy in the future. ${ }^{33}$ However, there is also a third potential failure, which may result in lower levels of satisfaction and acceptance and, thus, in further unwanted pregnancies: when a program cannot provide a wide range of contraceptive methods for postabortion clients.

Operations research conducted in postabortion settings has shown that offering a wide range of methods coupled with effective counseling increases contraceptive uptake. ${ }^{12,16}$ A limited choice of methods can lead to a woman selecting a method that she may be more likely to discontinue because it is ultimately less acceptable to her or her partner. Additionally, offering only short-acting methods to women who need and are eligible for longterm protection may result in unwanted pregnancy because the return to fertility after abortion is immediate and the chance of method failure is high with short-acting methods. To avoid this pitfall, it is vital to establish effective programs that offer a wide range of methods.

The quality of comprehensive abortion care may be limited by infrastructure that is often outdated and inappropriate for services that have moved from labor and delivery or surgical areas to stand-alone, predominately outpatient service areas. Comprehensive and acceptable abortion care requires that adequate infrastructure, a wide range of contraceptive methods in the procedure area, and all necessary equipment be available consistently. Providers well trained in both abortion and contraceptive services and who are motivated and supported to provide services are also key to success.

\section{Research Needed on Postabortion Method Mix}

To achieve positive results, postabortion services need to promote a contraceptive method mix acceptable and effective for young and single women who need long-term and reliable protection for their long reproductive lives ahead. LARC methods are private and provide continuous protection against unwanted pregnancy, with higher continuation rates than short-acting methods, while serving a range of clients' intentions to delay or space births.

However, evidence on the most acceptable method mix for postabortion clients is scarce. More health systems research is needed to assess method continuation and discontinuation rates and to evaluate the impact of improvements in PAFP services on contraceptive prevalence and whether such improvements result in lower maternal morbidity and mortality. ${ }^{34}$ 


\section{Balanced Method Availability Helps Prevent Repeat Abortions}

The package of interventions described here has set the groundwork for stronger postabortion contraception services. Postabortion contraception contributes to the prevention of unwanted pregnancy. Also, it contributes to increased contraceptive acceptance on a national level by addressing an often overlooked group of women with high demand for contraception. Focusing on promoting a more balanced method mix and improving access to LARC methods has led to higher levels of postabortion contraceptive method acceptance overall.

In conclusion, well-planned and organized PAFP services are a cost-effective, feasible, and easily replicable strategy for serving women, especially young women, with an unmet need for contraception who are highly vulnerable to a future unintended pregnancy and repeat abortion.

Acknowledgments: This article documents the intervention implemented by lpas Ethiopia in collaboration with the government health system at all levels to strengthen postabortion family planning services and expand contraceptive choice. We gratefully acknowledge the following institutions and their staff for successful implementation of the program: Federal Ministry of Health, SNNPR Regional Health Bureau, zonal and district health offices, the 101 intervention facilities, the lpas global office, the lpas country office, and lpas regional health system staff. The implementation and documentation of strengthening postabortion family planning services was made possible through the generous funding of an anonymous private donor. The findings, views, and conclusions are entirely those of the authors.

Competing Interests: None declared.

\section{REFERENCES}

1. Singh S, Fetters T, Gebreselassie H, Abdella A, Gebrehiwot Y, Kumbi $S$, et al. The estimated incidence of induced abortion in Ethiopia, 2008. Int Perspect Sex Reprod Health. 2010;36(1): 16-25. CrossRef. Medline

2. Sundaram A, Vlassoff $M$, Bankole A. Benefits of meeting the contraceptive needs of Ethiopian women. In Brief No. 1. New York: Guttmacher Institute; 2010. Available from: https:// www.guttmacher.org/pubs/IB-Contraceptive-Needs-Ethiopia.pdf

3. Central Statistical Agency [Ethiopia]; ICF International. Ethiopia demographic and health survey 2011. Calverton (MD): ICF International; 2012. Co-published by the Central Statistical Agency. Available from: http://www.dhsprogram.com/pubs/ pdf/FR255/FR255.pdf

4. World Health Organization (WHO). Post-abortion family planning: a practical guide for programme managers. Geneva: WHO; 1997. Available from: http://www.who.int/reproductivehealth/ publications/family_planning/RHT_97_20/en/

5. United Nations (UN). Report of the international conference on population and development, Cairo, 5-13 September 1994. New York: UN; 1995. Available from: https://www.unfpa.org/ sites/default/files/event-pdf/icpd_eng_2.pdf

6. Wolf $M$, Benson J. Meeting women's needs for post-abortion family planning: report of a Bellagio Technical Working Group. Int J Gynaecol Obstet. 1994;45 Suppl:S1-S33. CrossRef. Medline

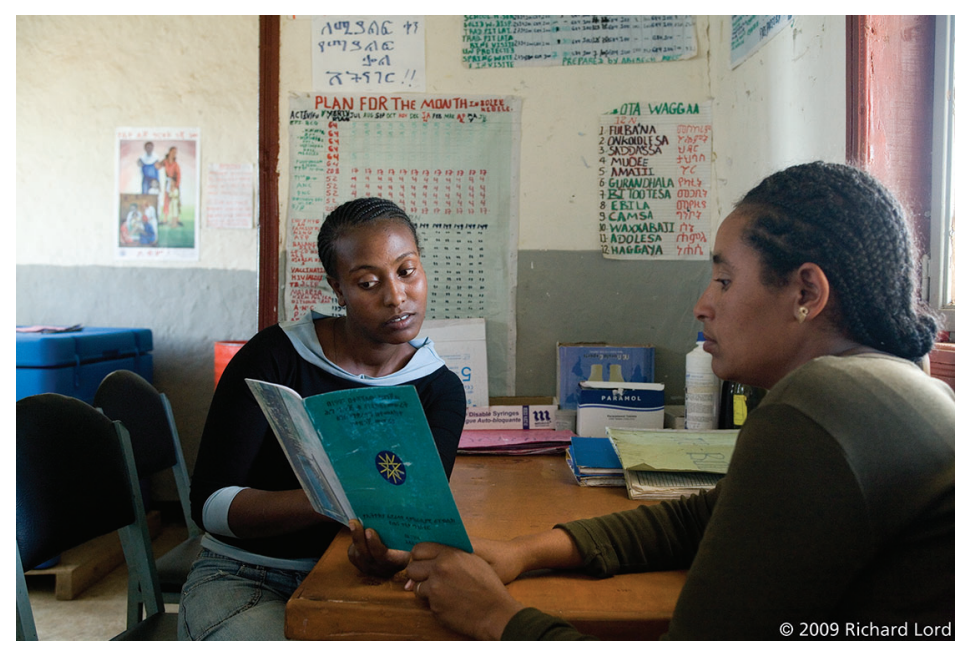

A mid-level provider discusses available contraceptive methods with a client to assist her in making an informed, voluntary contraceptive choice.

7. High Impact Practices in Family Planning (HIPs). Postabortion family planning: strengthening the family planning component of post abortion care. Washington (DC): United States Agency for International Development; 2012. Available from: https://wnw.fphigh impactpractices.org/resources/postabortion-family-planningstrengthening-family-planning-component-postabortion-care

8. International Federation of Gynecology and Obstetrics (FIGO), International Confederation of Midwives (ICM); International Council of Nurses (ICN); United States Agency for International Development (USAID); White Ribbon Alliance (WRA);

Department for International Development (DFID); Bill \& Melinda Gates Foundation. Post abortion family planning: a key component of post abortion care: consensus statement. Washington (DC); 2013. Available from: http://www.respondproject.org/pages/files/6_pubs/advocacy-materials/PAC-FPJoint-Statement-November2013-final.pdf

9. United States Agency for International Development (USAID). What works: a policy and program guide to the evidence on postabortion care. Washington (DC): USAID; 2007. Available from: http:// www. postabortioncare.org/sites/pac/files/Compendium.pdf

10. Otsea K, Benson J, Alemayehu T, Pearson E, Healy J. Testing the Safe Abortion Care model in Ethiopia to monitor service availability, use, and quality. Int J Gynecol Obstet. 2011;115(3): 316-321. CrossRef. Medline

11. Senlet $P$, Cagatay L, Ergin J, Mathis J. Bridging the gap: integrating family planning with abortion service in Turkey. Int Fam Plan Perspect. 2001;27(2):90-95. Available from: http:// www.guttmacher.org/pubs/journals/2709001.html

12. McDougall J, Fetters T, Clark KA, Rathavy T. Determinants of contraceptive acceptance among Cambodian abortion patients. Stud Fam Plann. 2009;40(2):123-132. CrossRef. Medline

13. Lema VM, Mpanga V. Post-abortion contraceptive acceptability in Blantyre, Malawi. East Afr Med J. 2000;77(9):488-493. Medline

14. Solo J, Billings DL, Aloo-Obunga $C$, Ominde A, Makumi M. Creating linkages between incomplete abortion treatment and family planning services in Kenya. Stud Fam Plann. 1999;30(1): 17-27. CrossRef. Medline

15. World Health Organization (WHO). Contraceptive method mix: guidelines for policy and service delivery. Geneva: WHO; 1994. Available from: http://apps.who.int/iris/handle/10665/39357 
16. Ross J, Keesbury J, Hardee K. Trends in the contraceptive method mix in low- and middle-income countries: analysis using a new "average deviation" measure. Glob Health Sci Pract. 2015;3(1): 34-55. CrossRef. Medline

17. Medina R, Vernon R, Mendoza I, Aguilar C. Expansion of postpartum/postabortion contraception in Honduras. New York: Population Council; 2001. Available from: http://pdf.usaid.gov/ pdf_docs/Pnacm374.pdf

18. Cleland J, Conde-Agudelo A, Peterson H, Ross J, Tsui A. Contraception and health. Lancet. 2012;380(9837):149-156. CrossRef. Medline

19. Zhu JL, Zhang WH, Cheng $Y, X u J, X u X$, Gibson D, et al. Impact of post-abortion family planning services on contraceptive use and abortion rate among young women in China: a cluster randomised trial. Eur J Contracept Reprod Health Care. 2009; 14(1):46-54. CrossRef. Medline

20. Johnson BR, Ndhlovu S, Farr SL, Chipato T. Reducing unplanned pregnancy and abortion in Zimbabwe through postabortion contraception. Stud Fam Plann. 2002;33(2):195-202. CrossRef. Medline

21. Azmat SK, Hameed W, Ishaque M, Mustafa G, Ahmed A. Postabortion care family planning use in Pakistan. Pak J Public Health. 2012;2(2):4-9. Available from: http://www.hsa.edu.pk/ journal/2013/June\%202012\%20Vol.\%202\%20No.\%202.pdf

22. Goodman S, Hendlish SK, Reeves MF, Foster-Rosales A. Impact of immediate postabortal insertion of intrauterine contraception on repeat abortion. Contraception. 2008;78(2):143-148. CrossRef. Medline

23. Federal Democratic Republic of Ethiopia, Ministry of Health (MOH). Technical and procedural guidelines for safe abortion services in Ethiopia. 2nd ed. Addis Ababa (Ethiopia): MOH; 2014.

24. Desta D, Geressu T. Assessment of the delivery of long-acting and permanent methods of contraception in Ethiopia: result of a baseline assessment in 346 public sector facilities in Tigray, Amhara, Oromiya and SNNP regional states. Addis Ababa (Ethiopia): Ipas Ethiopia; 2008.

25. Gebreselassie H, Fetters T. Responding to unsafe abortion in Ethiopia: a facility-based assessment of postabortion care services in public health sector facilities in Ethiopia. Chapel Hill (NC): Ipas; 2002. Available from: http://www.ipas.org/ $\sim /$ media/Files/lpas\%20Publications/EthiopiaUnsafeAb.ashx

26. Desta $D$, Alemayehu T. Integrating comprehensive contraceptive and abortion care services: making comprehensive contraceptive services available to Ethiopian women, 2008-12. Addis Ababa (Ethiopia): Ipas Ethiopia; 2013.
27. Kiggundu C. Decentralizing integrated postabortion care in Uganda: a pilot training and support initiative for improving the quality and availability of integrated RH service. Kampala (Uganda): Ministry of Health [Uganda]; 1999. Co-published by PRIME, Ipas, and DISH project.

28. Samuel M, Alemayehu T, Powell B. Quality improvement for comprehensive abortion care: approaches, progress and lessons from pilot implementation, 2009-12. Addis Ababa (Ethiopia): Ipas Ethiopia; 2013.

29. Federal Democratic Republic of Ethiopia, Ministry of Health $(\mathrm{MOH})$. Standards on youth friendly reproductive health services: service delivery guideline and minimum service delivery package on YFRH services. Addis Ababa (Ethiopia): $\mathrm{MOH}$; [200?]. Available from: http://phe-ethiopia.org/resadmin/uploads/ attachment-159-Stds_\&_Serv_GL_YFRH.pdf

30. Melkamu Y, Betre M, Tesfaye S. Utilization of post-abortion care services in three regional states of Ethiopia. Ethiop J Health Dev. 2010;24 Special Issue 1:123-129. Available from: http://ejhd. vib.no/ejhd-v24-sn1 / 124\%20Utilization\%20of\%20postabortion\%20care\%20services\%20in\%20three\%20regi.pdf

31. Wanjiru M, Askew I, Munguti N, RamaRao S, Homan R, Kahando $R$, et al. Assessing the feasibility, acceptability and cost of introducing comprehensive postabortion care in health centres and dispensaries in rural Tanzania: final report. New York: EngenderHealth, ACQUIRE Project; 2007. Co-published by Population Council, FRONTIERS in Reproductive Health Program. Available from: http://www.engenderhealth.org/files/pubs/ acquire-digital-archive/6.0_integrate_fp-lapms/6.2_resources/ 6.2.2_studies/tanzania_pac.pdf

32. Takele A, Degu G, Yitayal M. Demand for long acting and permanent methods of contraceptives and factors for non-use among married women of Goba Town, Bale Zone, South East Ethiopia. Reprod Health: 2012;9:26. CrossRef. Medline

33. Verme CS. Postabortion care: a global health issue [videocassette]. Nahitchevansky G, Webb Productions, producer. Washington (DC): Post abortion Care Consortium (AVSC International, International Planned Parenthood Federation, International Projects Assistance Services, JHPIEGO Corporation, Pathfinder International); 1994. 1 videocassette: $12 \mathrm{~min}$., NTSC format.

34. Tripney J, Kwan I, Bird KS. Postabortion family planning counseling and services for women in low-income countries: a systematic review. Contraception. 2013;87(1):17-25. CrossRef. Medline

\section{Peer Reviewed}

Received: 2015 Sep 30; Accepted: 2016 Jan 11

Cite this article as: Samuel M, Fetters T, Desta D. Strengthening postabortion family planning services in Ethiopia: expanding contraceptive choice and improving access to long-acting reversible contraception. Glob Health Sci Pract. 2016;4 Suppl 2:S60-S72. http://dx.doi.org/10.9745/ GHSP-D-15-00301.

(c) Samuel et al. This is an open-access article distributed under the terms of the Creative Commons Attribution License, which permits unrestricted use, distribution, and reproduction in any medium, provided the original author and source are properly cited. To view a copy of the license, visit $\mathrm{http}: / /$ creativecommons.org/licenses/by/3.0/. When linking to this article, please use the following permanent link: http://dx.doi.org/10.9745/GHSP-D$15-00301$. 